\title{
RANCANG BANGUN APLIKASI DATA KK DAN KTP PENDUKUNG APLIKASI E- KTP NASIONAL DI KECAMATAN TOMO BERBASIS WEB MENGGUNAKAN FRAMEWORK CODEIGNITER
}

\author{
Suhendri \\ Program Studi Informatika, Fakultas Teknik, Universitas Majalengka \\ email: suh@ft.unma.ac.id / theprof.suhendri@yahoo.co.id
}

\begin{abstract}
Observations conducted in Tomo Subdistrict Sumedang District that the system is running in the process of data management $K K$ and KTP already using the application is the national E-ID card application, where the application is often experiencing disruptions such as internet network breaking up, access is too slow because it is divided into all Indonesia, there are data redudancy with different NIK, KK and KTP data erased due to error, KK and KTP data become inaccurate because E-KTP application can only be accessed by Oparator (Pegawai) Kecamatan and other problems. Population data processing (KK and KTP data) can still be done using national E-ID card application but because some weaknesses or weaknesses are found, it is needed supporting application that can be accessed by all citizens so that data can be controlled well with inputs from the community. By looking at the weaknesses of the system that is running, it is proposed a new system that is with the design of data applications KK and KTP as a supporter of national E-ID card web-based using codeigniter framework as an alternative solution. The purpose of this research is to design the application of Data of KK and $K T P$ in order to facilitate Tomo Sub district community to access and check their data of KK and KTP online, build KK and KTP data application as supporting of national E-KTP application in Tomo Subdistrict which often experience disturbance and help the community of District Tomo to check the data and build application of Data KK and KTP to facilitate the District Tomo in the process of checking the population data so that it can monitor the population data well.
\end{abstract}

Keywords: Design, KK and KTP Data Applications, E-KTP Application, Tomo Sub-district, CodeIgniter Framework

\section{PENDAHULUAN}

Administrasi kependudukan sebagai salah satu sistem bagi penduduk yang diharapkan dapat memberikan pemenuhan atas hak-hak administrasi penduduk dalam pelayanan publik serta memberikan perlindungan yang berkenan dengan penerbitan dikumen kependudukan tanpa adanya perlakuan yang diskriminatif melalui peran aktif pemerintah dan pemerintah daerah.

Penerapan E-KTP yang sedang dilaksanakan merupakan bagian dari upaya untuk mempercepat dan mendukung akurasi terbangunnya database kependudukan yang terintegrasi di seluruh kabupaten/kota, povinsi maupun database kependudukan secara nasional.

Penerapan E-KTP secara nasional merupakan hal yang penting dalam penataan sistem administrasi kependudukan sesuai dengan amanat undang - undang nomor 23 tahun 2006 tentang administrasi kependudukan. Adapun beberapa manfaat E-KTP yang diharapkan seperti mencegah dan menutupnya peluang adanya KTP ganda dan KTP palsu, untuk mendukung terwujudnya database kependudukan yang akurat, dapat mendukung peningkatan keamanan Negara sebagai dampak positif dari peluang KTP ganda dan KTP palsu, mempermudah masyarakat untuk mendapatkan pelayanan untuk pengurusan berbagai izin dari lembaga pemerintahan, dan NIK di E-KTP untuk menjadi dasar penerbitan SIM, NPWP, paspor.

Berbagai upaya telah dilakukan untuk mensukseskan program E-KTP termasuk percepatan pada tahun 2014, pemerintah telah melakukan koordinasi antar instansi dan antar daerah, membentuk sistem, pedoman, dan standar serta melakukan pembinaan, pembimbingan, supervise, pemantauan, evaluasi dan konsultasi kepada pemerintah daerah kabupaten / kota.

Evaluasi yang dilakukan juga dapat menjadi 
tolak ukur untuk program E-KTP yang telah di laksanakan di Indonesia. Evaluasi yang di lakukan mulai dari perencanaan program, penerapan, permasalahan dan kegagalan yang terjadi dalam penerapaan E-KTP yang dilakukan di Indonesia. Hasil evaluasi ini juga dapat menjadi referensi untuk mendapatkan sebuah solusi dari permasalahan yang sedang dialami dalam pemgimplementasian E-KTP di Indonesia.

Setiap kendala yang dijumpai dalam pengimplementasian yang sudah dilakukan seperti kurangnya peralatan yang diberikan di beberapa daerah - daerah. Serta ketersediaan daya listrik diseluruh kecamatan / tempat pelayanan E-KTP sekabupaten karena belum tersedianya anggaran untuk pembelian genset yang mencukupi, biaya bahan bakar relative mahal dan susahnya dijangkau, serta memerlukan waktu lama dalam proses pengadaan pembelian genset. Kendala yang di hadapi dapat menjadi pembelajaran agar program E-KTP ini dapat berjalan lebih baik ke depannya.

Berdasarkan observasi yang dilakukan di Kecamatan Tomo Kabupaten Sumedang bahwa pada sistem yang sedang berjalan dalam proses pengelolaan data KK dan KTP sudah menggunakan aplikasi yaitu aplikasi E-KTP nasional, dimana aplikasi tersebut sering mengalami gangguan seperti jaringan internet putus, akses terlalu lambat karena dibagi ke seluruh Indonesia, terjadi data redudancy (kerangkapan data) dengan NIK berbeda, data KK dan KTP terhapus karena error, data KK dan KTP menjadi tidak akurat karena aplikasi E-KTP hanya bisa diakses oleh Oparator (Pegawai) Kecamatan serta masalah yang lainnya.

Aplikasi E-KTP nasional yang sering mengalami gangguan dan masalah maka warga masyarakat banyak yang dirugikan bukan hanya pelayanan pembuatan KK dan KTP saja tetapi juga keasalahan atau kehilangan data karena error system, oleh karena itu aplikasi pendukung sangat diperlukan untuk mencegah terjadinya permasalahan yang ditimbul di Kecamatan.

Pengolahan data penduduk (data KK dan KTP) tetap dapat dilakukan menggunakan aplikasi E-KTP nasional namun karena ditemukan beberapa kekurangan atau kelemahannya maka diperlukan aplikasi pendukung yang bisa diakses oleh seluruh warga masyarakat sehingga data dapat terkontrol dengan baik dengan masukan-masukan dari warga masyarakat. Dengan melihat kelemahan-kelemahan dari sistem yang sedang berjalan, maka diusulkan sistem yang baru yaitu dengan rancang bangun aplikasi data KK dan KTP sebagai pendukung aplikasi E-KTP nasional berbasis web menggunakan framework codeigniter sebagai alternatif pemecahannya.

Pengolahan data menggunakan sistem yang diusulkan memungkinkan pengolahan data tetap dilakukan oleh Operator (Pegawai) Kecamatan sebagai backup atau pendukung aplikasi E-KTP nasional namun bisa diakses juga data $\mathrm{KK}$ dan KTP-nya oleh warga masyarakatnya.

Tujuan penelitian ini adalah sebagai berikut:

1. Merancang aplikasi Data KK dan KTP agar memudahkan warga masyarakat Kecamatan Tomo dalam mengakses dan mengecek data KK dan KTP-nya secara online.

2. Membangun aplikasi Data KK dan KTP sebagai pendukung aplikasi E-KTP nasional di Kecamatan Tomo yang sering mengalami gangguan dan membantu warga masyarakat Kecamatan Tomo untuk melakukan pengecekan datanya.

3. Membangun aplikasi Data KK dan KTP agar mempermudah pihak Kecamatan Tomo dalam proses pengecekan data penduduk sehingga dapat me-monitoring data penduduk dengan baik.

Berikut beberapa tinjauan pustaka yang linier dengan penelitian ini :

Slamet, D., dkk., 2012, Pengembangan Sistem Informasi Administrasi Kependudukan (SIAK) Pada Bagian Pendaftaran Pindah Datang Penduduk Di Dinas Kependudukan Dan Pencatatan Sipil Kabupaten Garut, Jurnal Algoritma Sekolah Tinggi Teknologi Garut.

Adianto, D., \& Sujadi, H. (2016). Aplikasi Sistem Pendukung Keputusan Pemilihan Jurusan Siswa-Siswi Sma (Mipa/Ips/Bahasa) Menggunakan Metode Ahp.

\section{METODE PENELITIAN}

Metode penelitian menjelaskan rancangan kegiatan, ruang lingkup atau objek, bahan dan alat utama, tempat, teknik pengumpulan data, definisi operasional variabel penelitian, dan teknik analisis

1. Metodologi Pengembangan Sistem Systems Development Life Cycle (SDLC) 
merupakan metodologi umum dalam pengembangan sistem yang menandai kemajuan usaha analisis dan desain.

SDLC meliputi fase-fase yang menjadi prosesproses standar berikut:

1. Identifikasi dan seleksi proyek

2. Inisiasi dan perencanaan proyek

3. Analisis

4. Desain
a Desain logikal
b Desain fisikal

5. Implementasi

6. Pemeliharaan

Model siklus hidup (life cycle model), adalah model utama dan dasar dari banyak model. Salah satu model yang cukup dikenal dalam dunia rekayasa perangkat lunak adalah The Waterfall Model. Ada 5 tahapan utama dalam The Waterfall Model seperti terlihat pada gambar 3.2. Disebut waterfall (berarti air terjun) karena memang diagram tahapan prosesnya mirip dengan air terjun yang bertingkat. Model ini mengambil kegiatan proses dasar seperti spesifikasi, pengembangan, validasi, evolusi, dan mempresentasikannya sebagai fase-fase proses yang berbeda seperti spesifikasi persyaratan, perancangan perangkat lunak, implementasi, pengujian, dan seterusnya.

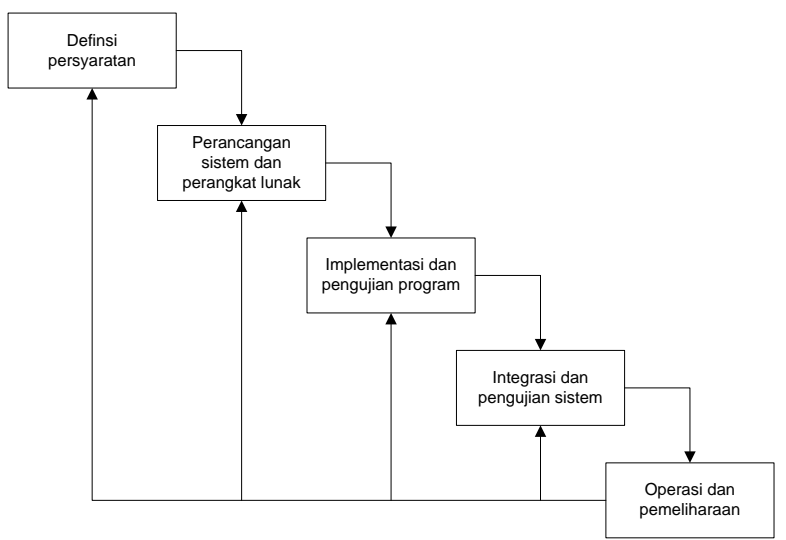

Gambar 1. Model Waterfall (Ian Sommerville, 2003:43)

Tahap-tahap utama dari model ini memetakan kegiatan-kegiatan pengembangan dasar yaitu :

1. Analisis dan definisi persyaratan. Pelayanan, batasan, dan tujuan sistem ditentukan melalui konsultasi dengan user sistem. Persyaratan ini kemudian didefinisikan secara rinci dan berfungsi sebagai spesifikasi sistem.

2. Perancangan sistem dan perangkat lunak. Proses perancangan sistem membagi persyaratan dalam sistem perangkat keras atau perangkat lunak. Kegiatan ini menentukan arsitektur sistem secara keseluruhan. Perancangan perangkat lunak melibatkan identifikasi dan deskripsi abstraksi sistem perangkat lunak yang mendasar dan hubungan-hubungannya.

3. Implementasi dan pengujian unit. Pada tahap ini, perancangan perangkat lunak direalisasikan sebagai serangkaian program atau unit program. Pengujian unit melibatkan verifikasi bahwa setiap unit telah memenuhi spesifikasi.

4. Integrasi dan pengujian sistem. Unit program atau program individual diintegrasikan dan diuji sebagai sistem yang lengkap untuk menjamin bahwa persyaratan sistem telah dipenuhi. Setelah pengujian sistem, perangkat lunak dikirim kepada pengguna.

5. Operasi dan pemeliharaan. Biasanya (walaupun tidak seharusnya), ini merupakan fase siklus hidup yang paling lama. Sistem diinstal dan dipakai. Pemeliharaan mencakup koreksi dari berbagai error yang tidak ditemukan pada tahap-tahap terdahulu, perbaikan atas implementasi unit sistem dan pengembangan pelayanan sistem, sementara persyaratan - persyaratan baru ditambahkan.

\section{Teknik Pengumpulan Data}

Proses penelitian yang dilakukan Penulis di lapangan lebih jelasnya dengan metode observasi (pengamatan), metode wawancara dan metode studi literatur.

1. Metode Observasi

Pengumpulan informasi dilakukan dengan observasi langsung (komunikasi dua arah) di Kecamatan Tomo Kabupaten Sumedang serta melakukan analisa permasalahan yang merupakan kebutuhan untuk mendapatkan informasi-informasi yang menunjang dalam rancang bangun aplikasi data KK dan KTP.

2. Metode Wawancara

Metode ini dilakukan dengan cara bertanyajawab langsung dengan narasumber yaitu Camat dan Pegawai Kecamatan Tomo Kabupaten Sumedang yang berkaitan dengan objek penelitian yaitu rancang bangun aplikasi data KK dan KTP sebagai pendukung aplikasi E-KTP nasional berbasis web framework codeigniter.

3. Metode Studi Literatur

Untuk memperoleh informasi tentang 
rancang bangun aplikasi data KK dan KTP sebagai pendukung aplikasi E-KTP nasional berbasis web menggunakan framework codeigniter dilakukan studi literatur melalui buku-buku referensi dan sumber informasi lainnya.

\section{Tempat Penelitian}

Objek penelitian ini adalah Kecamatan Tomo Kabupaten Sumedang. Berikut ini merupakan uraiannya Profil Kecamatan Tomo Kabupaten Sumedang.

Dengan berakhirnya masa jabaran bupati dan Wakil Bupati Sumedang periode 2008-2013, dan dalam rangka menyongsong pemerintahan baru Bupati dan Wakil Bupati Sumedang terpilih periode 2013-2018 dengan tahap mengacu pada program pembangunan jangka menengah serta jangka panjang Kabupaten Sumedang, maka Kecamatan Tomo pada program jangka menengah (5 tahun) kedepan mempunyai VISI : "Terwujudnya Kecamatan Tomo yang Semarak ( Sejahtera, Maju, Resik, Agamis dan Kreatif) pada tahun 2018.

Salah satunya menyebutkan bahwa untuk instansi pemerintah yang di wajibkan tidak hanya yang membuat rencana strategis, tetapi di kembangkan sampai yang memimpin kerja. Rencana Strategis merupakan dokumen resmi daerah dalam menentukan langkah-langkah pembangunan yang akan dilaksanakan melalui proses secara sistematis terorganisasi dan berkelanjutan untuk mencapai visi misi daerah yang penjabarannya melalui pelaksanaan teknis di SKPD sesuai dengan tugas pokok dan fungsi masing-masing dan menjadi pedoman dalam melaksanakan berbagai program kegiatan.

Peraturan pemerintah Nomor 108 tahin 2000 tentang Tata Cara Pertanggung Jawaban Kepala Daerah yang menyebutkan bahwa Renstra atau Dokumen Perencanaan Daerah lainnya yang disahkan dan Kepala Daerah yang selanjutnya di seut Rencana Strategis adalah rencana lima tahun yang menggambarkan visi, misi, tujuan, strategis, program dan Kegiatan.

Adapun dalam peenyusunan Renstra SKPD yaitu dengan menetapkan Visi dan Misi SKPD yang kemudian di tetapkan sasaran yang akan dicapai dalam kurun waktu 5 (lima) tahun kedepan. Pada setiap sasaran ditentukan strategi dan arah kebujakan tahunan yang tersusun dalam sebuah dokumen perencanaan kinerja atau Rencana Strategis Kecamatan Tomo tahun 2013-2018 adalah dimana Renstra Tomo 2013-2018 merupakan penjabaran dari Rencana Pembangunan Jangka Menengah Daerah Kabupaten Sumedang 2013-2018, yaitu penjabaran dari capaian-capaian sasaran yang ditargetkan ke dalam program dan kegiatan Kecamatan Tomo selama lima tahun. Sasaransasaran dalam RPJMD pada umumnya perlu ditindaklanjuti dengan program dan kegiatan di tingkat kecamatan dengan menggunakan pendekatan. Pendekatan ini digunakan untuk memilah sasaran mana yang menjadi kegiatan kecamatan dan sasaran lain sebagai pendukung atau penunjang.

\section{HASIL DAN PEMBAHASAN}

Diagram konteks pada aplikasi data KK dan KTP ini dapat dilihat pada gambar 2.

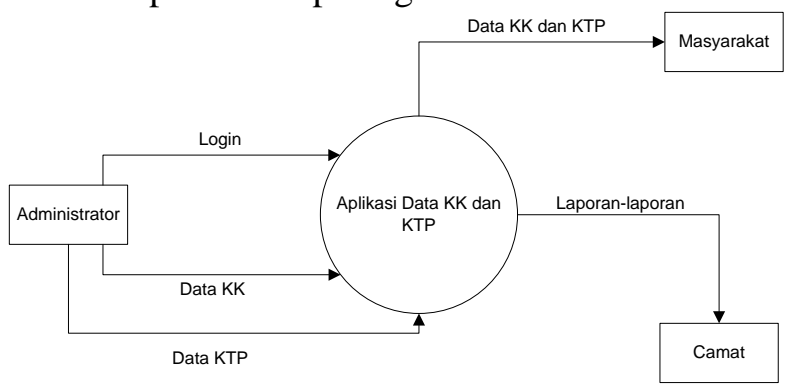

Gambar 2. Diagram Konteks/DFD Level 0 DFD untuk aplikasi ini adalah sebagai berikut :

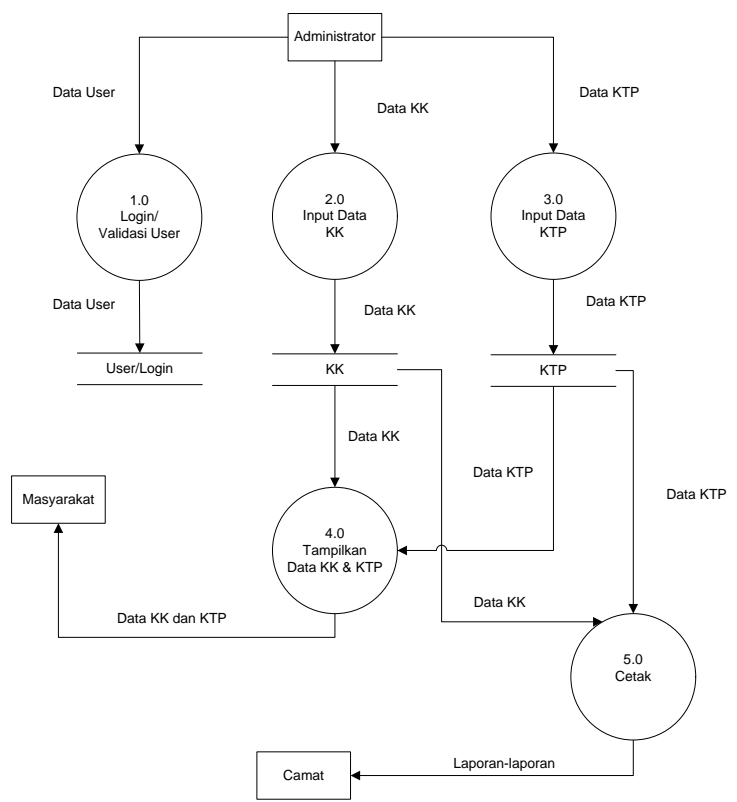

Gambar 3. DFD Level 1

Diagram E-R menyatakan hubungan antar 
entitas yang ada dalam aplikasi ini yang terdiri dari seperti gambar dibawah ini :

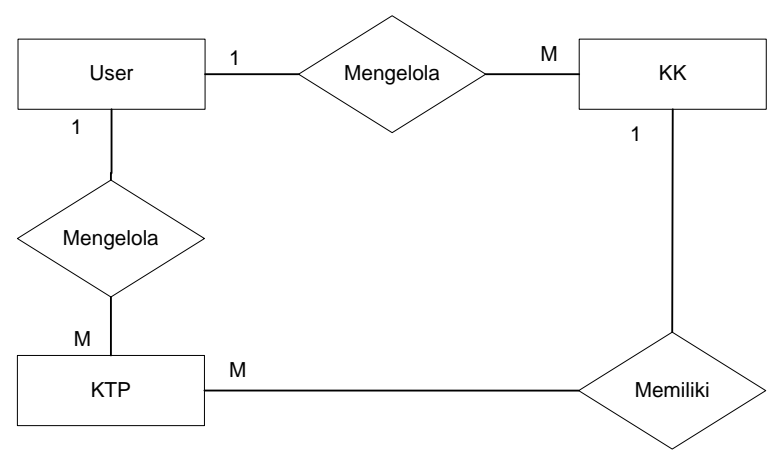

Gambar 4. Diagram E-R

Kamus data yang menjelaskan mengenai karakteristik/properti dari setiap entitas pada Diagram E-R yang dapat dilihat pada gambar 4.7 akan diuraikan sebagai berikut :

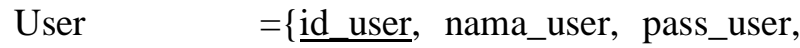
nama, level, status

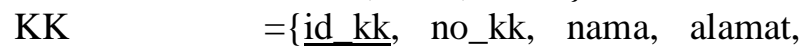
tgl_kk, keterangan\}

KTP $=\{\underline{\text { id_ktp }}$, nik, nama, alamat, tgl_ktp, keterangan

Struktur tabel yang digunakan untuk pembuatan sistem informasi ini adalah sebagai berikut :
1. Nama Tabel : User (Login)
Kunci
: id_user
Media
: Disk

Tabel 1. Struktur Tabel Data User (Login)

\begin{tabular}{|l|l|l|l|l|}
\hline $\begin{array}{c}\text { N } \\
\text { o }\end{array}$ & \multicolumn{1}{|c|}{$\begin{array}{c}\text { Nama } \\
\text { Kolom }\end{array}$} & \multicolumn{1}{|c|}{ Tipe } & Panjang & Keterangan \\
\hline 1 & id_user & int & 2 & $\begin{array}{l}\text { Primary } \\
\text { Key, AI }\end{array}$ \\
\hline 2 & nama_user & varchar & 20 & \\
\hline 3 & pass_user & varchar & 20 & \\
\hline 4 & nama & varchar & 200 & \\
\hline 5 & level & enum & ' 1 ', '2' & \\
\hline 6 & status & enum & ' 1 ', ' 0 ' & \\
\hline
\end{tabular}

\section{Nama Tabel : KK \\ Kunci : id_kk \\ Media : Disk}

Tabel 2. Struktur Tabel Data KK

\begin{tabular}{|l|l|l|l|l|}
\hline No & $\begin{array}{l}\text { Nama } \\
\text { Kolom }\end{array}$ & Tipe & Panjang & Keterangan \\
\hline 1 & id_kk & int & 4 & $\begin{array}{l}\text { Primary } \\
\text { Key, AI }\end{array}$ \\
\hline 2 & no_kk & varchar & 30 & \\
\hline 3 & nama & varchar & 100 & \\
\hline 4 & alamat & text & - & \\
\hline
\end{tabular}

\begin{tabular}{|l|l|l|l|l|}
\hline No & $\begin{array}{l}\text { Nama } \\
\text { Kolom }\end{array}$ & Tipe & Panjang & Keterangan \\
\hline 5 & tgl_kk & date & - & \\
\hline 6 & keterangan & text & - & \\
\hline
\end{tabular}

$\begin{array}{ll}\text { 3. Nama file } & \text { : KTP } \\ \text { Kunci } & : \text { id_ktp } \\ \text { Media } & : \text { Disk }\end{array}$

Tabel 3. Struktur Tabel Data KTP

\begin{tabular}{|l|l|l|l|l|}
\hline No & $\begin{array}{l}\text { Nama } \\
\text { Kolom }\end{array}$ & Tipe & Panjang & Keterangan \\
\hline 1 & id_ktp & int & 4 & $\begin{array}{l}\text { Primary } \\
\text { Key, AI }\end{array}$ \\
\hline 2 & nik & varchar & 30 & \\
\hline 3 & nama & varchar & 100 & \\
\hline 4 & alamat & text & - & \\
\hline 5 & tgl_ktp & date & - & \\
\hline 6 & keterangan & text & - & \\
\hline
\end{tabular}

Perancangan antarmuka merupakan rancangan dari percakapan antara pemakai dengan komputer. Rancangan antarmuka ini berisi proses pemasukkan data, menampilkan output informasi kepada pemakai atau keduanya melalui layar.

1. Tampilan Layar Aplikasi Untuk Masyarakat Umum

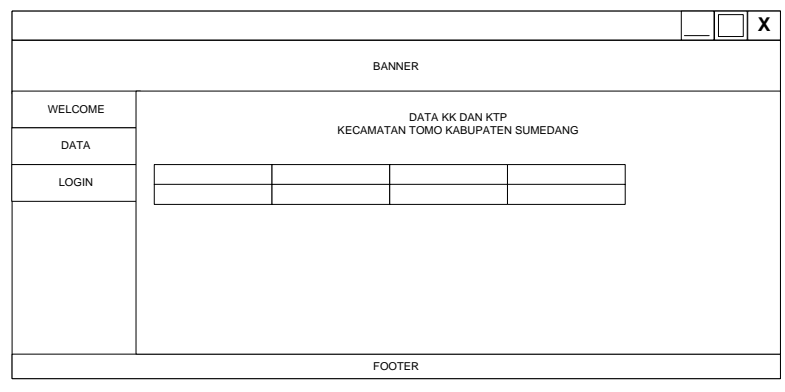

Gambar 5. Rancangan Menu Data KK dan KTP

2. Tampilan Layar Aplikasi Untuk Admin

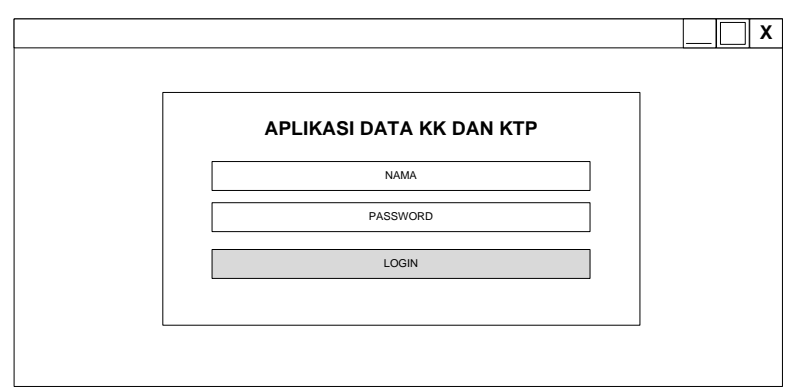

Gambar 6. Rancangan Menu Login 


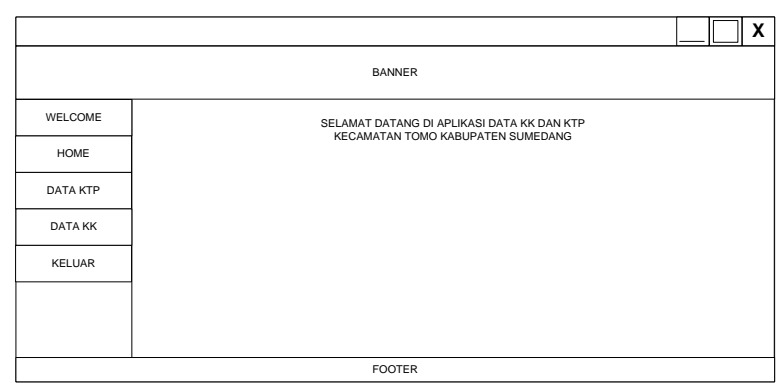

Gambar 7. Rancangan Menu Home

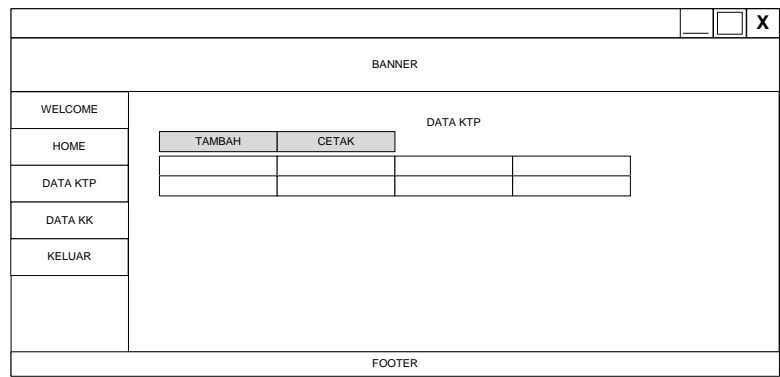

Gambar 8. Rancangan Menu Data KTP

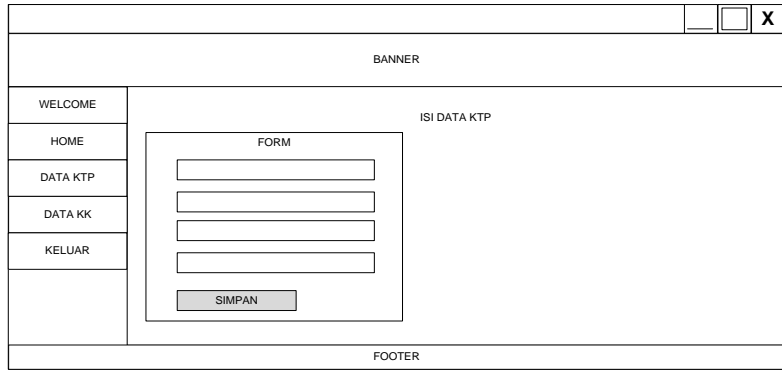

Gambar 9.Rancangan Menu Tambah Data KTP

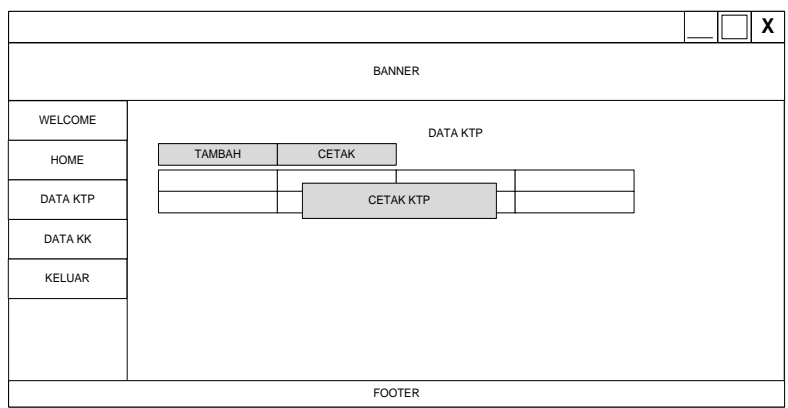

Gambar 10. Rancangan Menu Cetak Data KTP

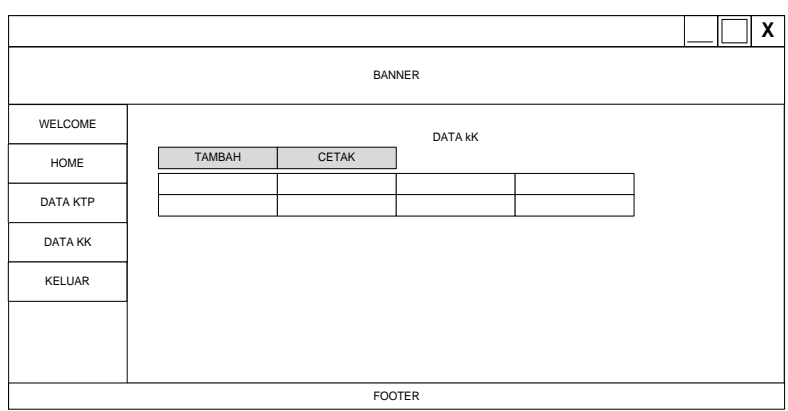

Gambar 11. Rancangan Menu Data KK

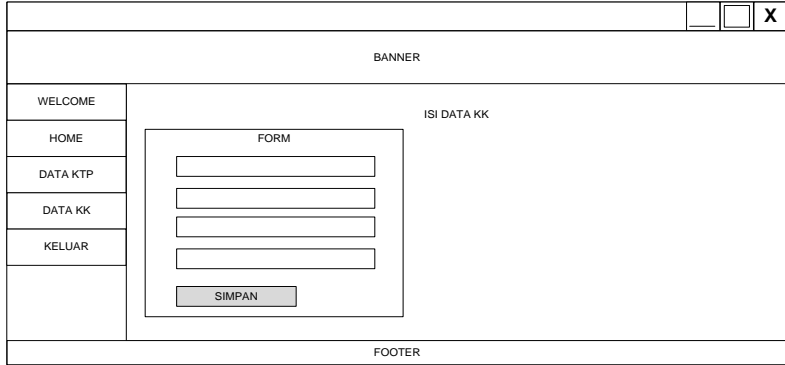

Gambar 12. Rancangan Menu Tambah Data KK

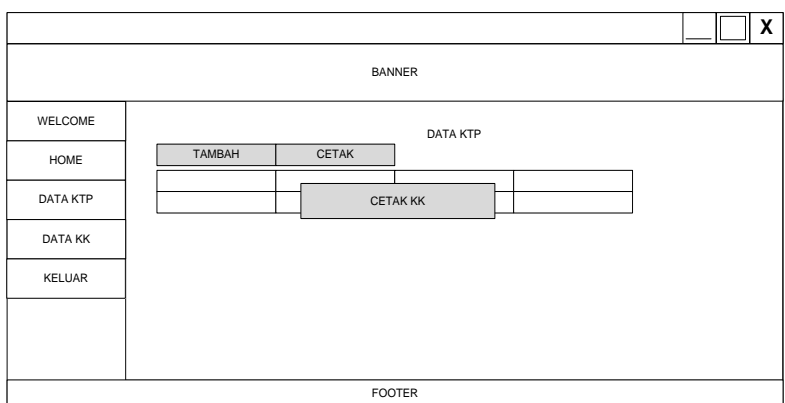

Gambar 13, Rancangan Menu Cetak Data KK Implementasi sistem ini berisi tentang dokumentasi aplikasi yang meliputi tampilan layar aplikasi dan hasil pencetakkan dari aplikasi.

1. Tampilan Layar Aplikasi Untuk Masyarakat Umum

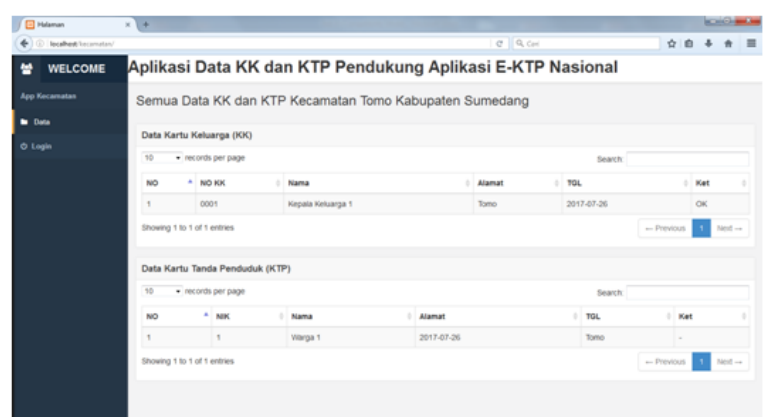

Gambar 14. Tampilan Menu Data KK dan KTP

2. Tampilan Layar Aplikasi Untuk Admin

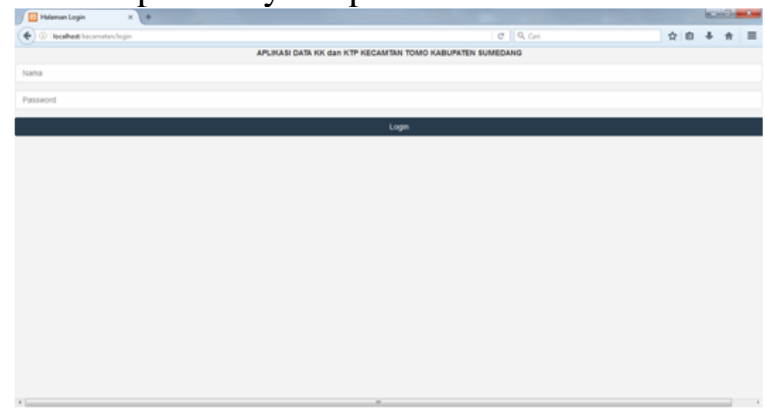

Gambar 15. Tampilan Menu Login 


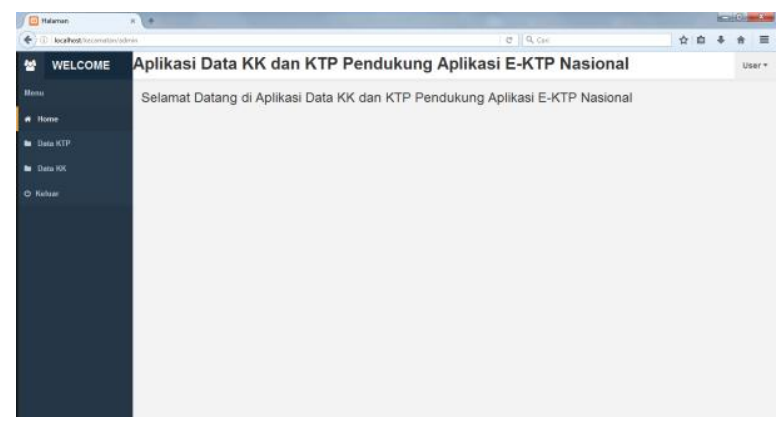

Gambar 16. Tampilan Menu Home

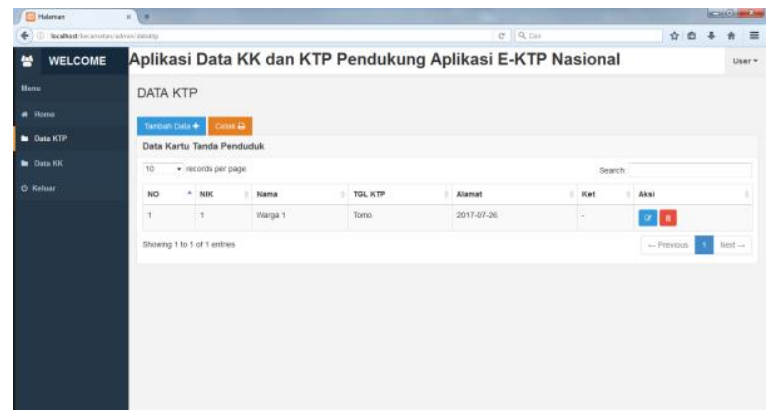

Gambar 17. Tampilan Menu Data KTP

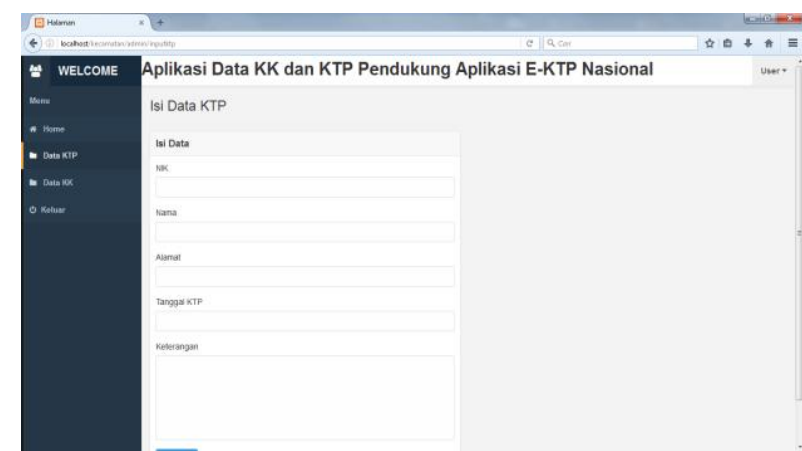

Gambar 18. Tampilan Menu Tambah Data KTP

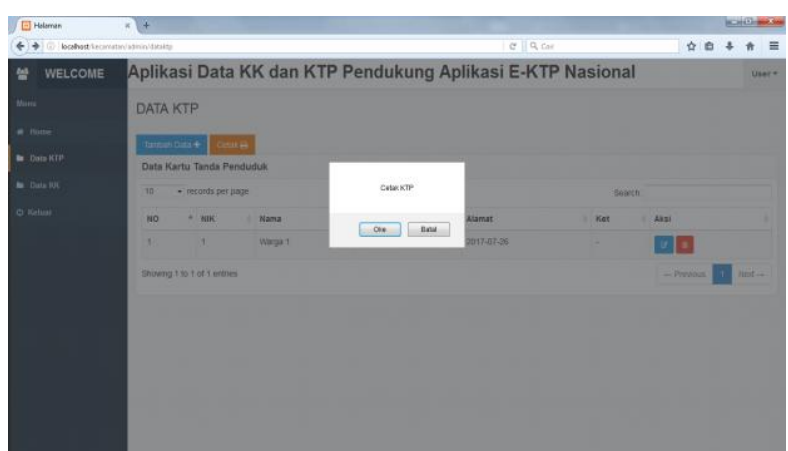

Gambar 19. Tampilan Menu Cetak Data KTP

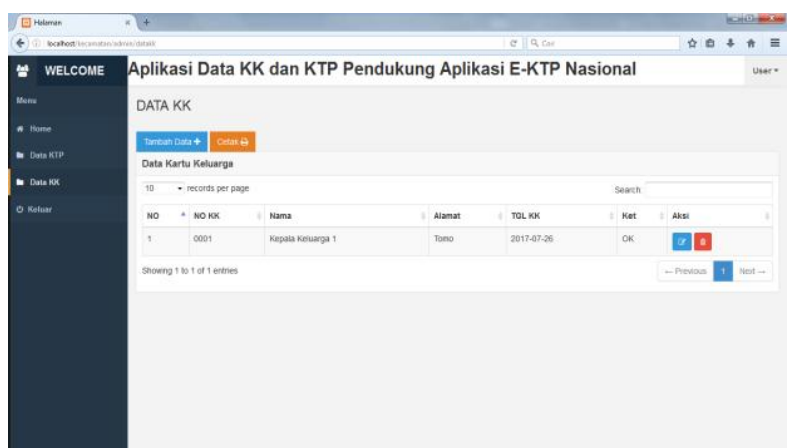

Gambar 20. Tampilan Menu Data KK

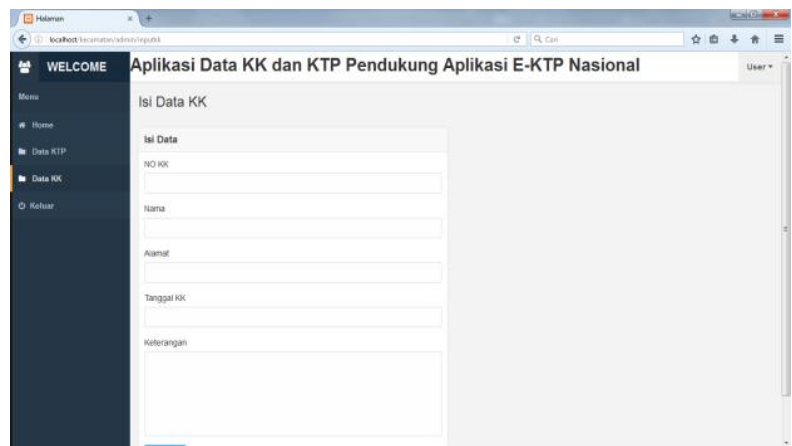

Gambar 21. Tampilan Menu Tambah Data KK

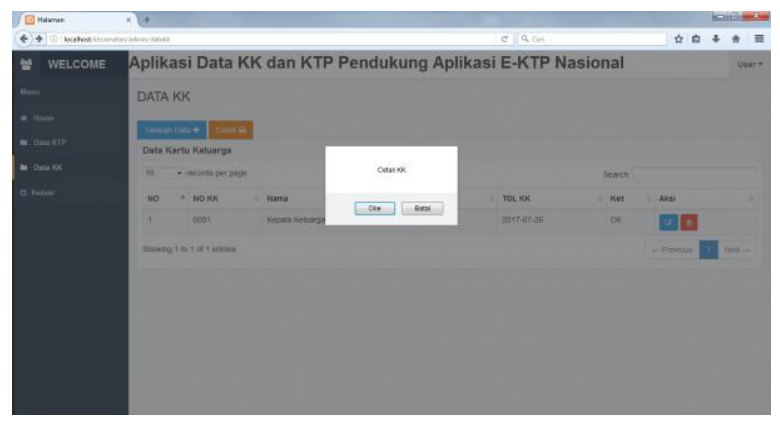

Gambar 22. Tampilan Menu Cetak Data KK

\section{KESIMPULAN}

Berdasarkan hasil dan pembahasan pada penelitian ini, maka penulis menarik beberapa kesimpulan sebagai berikut:

1. Aplikasi Data KK dan KTP ini dirancang dengan bahasa pemrograman PHP dan MySQL menggunakan Framework CodeIgniter sehingga berbasis web. Dengan berbasis web memudahkan warga masyarakat Kecamatan Tomo dalam mengakses dan mengecek data KK dan KTP-nya secara online.

2. Aplikasi ini dibangun sebagai pendukung aplikasi E-KTP nasional di Kecamatan Tomo yang sering mengalami gangguan atau untuk membantu warga masyarakat Kecamatan Tomo untuk memastikan bahwa data KK dan 
KTP-nya ada dan benar, tidak rangkap serta akurat.

3. Aplikasi ini dibangun untuk mempermudah pihak Kecamatan Tomo dalam proses pengecekan data penduduk sehingga dapat memonitoring data penduduk dengan baik.

\section{REFERENSI}

Al Fatta, H., 2007, Analisis dan Perancangan Sistem Informasi untuk Keunggulan Bersaing Perusahaan \& Organisasi Modern, ANDI : Yogyakarta.

A.S. Rosa, M. Shalahuddin, 2011, Modul Pembelajaran Rekayasa Perangkat Lunak (Terstruktur dan Berorientasi Objek), MODULA : Bandung.

Adianto, D., \& Sujadi, H. (2016). Aplikasi Sistem Pendukung Keputusan Pemilihan Jurusan Siswa-Siswi Sma (Mipa/Ips/Bahasa) Menggunakan Metode Ahp. J-Ensitec, 3(01).

Ian Sommerville. (2003), Software Engineering (Rekayasa Perangkat Lunak)/Ian Sommerville; alih bahasa, Dra.Yuhilza Hanum M.Eng, ; Hilarius Wibi Hardani. Ed.6, Erlangga, Jakarta

Nugroho, B., 2004, Aplikasi Pemrograman Web Dinamis dengan PHP dan MySQL, GAVA MEDIA : Yogyakarta.

Slamet, D., dkk., 2012, Pengembangan Sistem Informasi Administrasi Kependudukan (SIAK) Pada Bagian Pendaftaran Pindah Datang Penduduk Di Dinas Kependudukan Dan Pencatatan Sipil Kabupaten Garut, Jurnal Algoritma Sekolah Tinggi Teknologi Garut ISSN : 2302-7339 Vol. 09 No. 042012. 